\title{
Aryne Compatible Solvents are not Always Innocent
}

\author{
Sung-Eun Suh and David M. Chenoweth* \\ Department of Chemistry, University of Pennsylvania, 231 34th Street, \\ Philadelphia, Pennsylvania 19104-6323, United States
}

Table of content

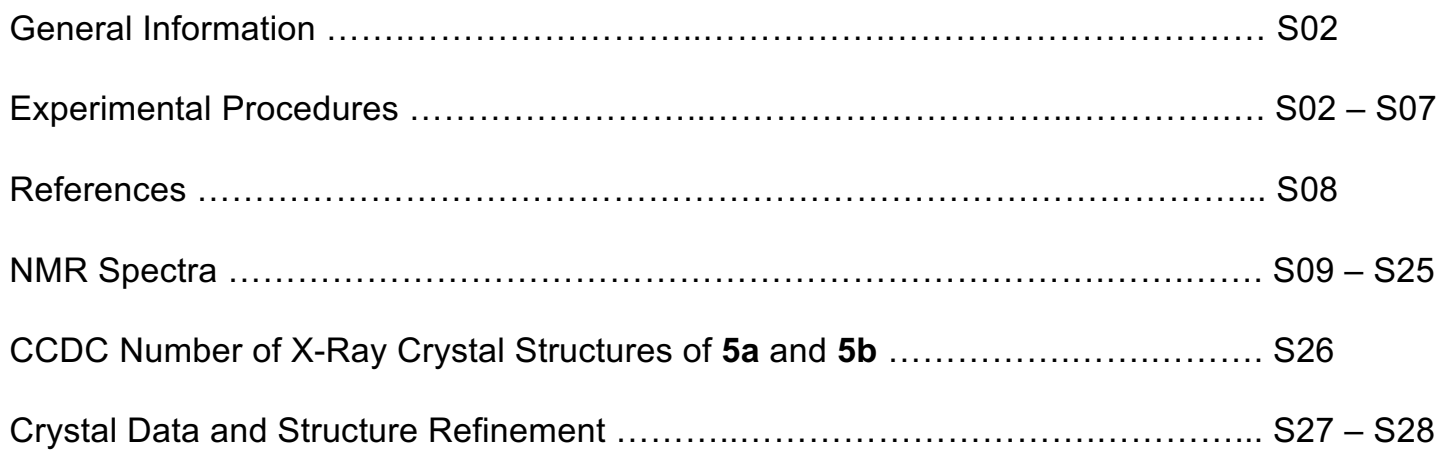




\section{General Information}

All commercial reagents and solvents were used as received. Flash column chromatography was performed using Silicycle silica gel (55-65 A pore diameter). Thin-layer chromatography was performed on Sorbent Technologies silica plates $\left(250 \mu \mathrm{m}\right.$ thickness). Proton nuclear magnetic resonance spectroscopy $\left({ }^{1} \mathrm{H} N M R\right)$ and Carbon nuclear magnetic resonance spectroscopy ${ }^{(13} \mathrm{C}$ NMR) spectra were recorded on a Bruker DMX $500{ }^{1} \mathrm{H}$ NMR. High-resolution mass spectra were obtained by Dr. Rakesh Kohli at the University of Pennsylvania's Mass Spectrometry Service Center on a on a Waters LC-TOF mass spectrometer (model LCT-XE Premier) using electrospray ionization. X-ray diffraction data obtained and solved by Dr. Patrick Carroll at the University of Pennsylvania. High performance liquid chromatography analysis was performed using a Jasco HPLC instrument equipped with a Phenomenex column (Luna 5u C18(2) 100A; $250 \times 4.60 \mathrm{~mm}, 5 \mu \mathrm{m}$ ).

\section{Experimental Procedures}

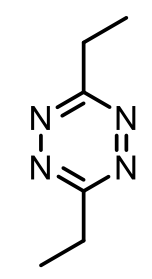

1

3,6-diethyl-1,2,4,5-tetrazine (1): Synthetic method and characterization data of 1 have been reported in our previous publication. ${ }^{1}$

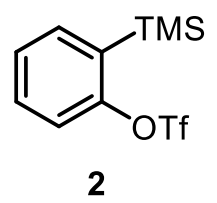

2-(trimethylsilyl)phenyl trifluoromethanesulfonate (2): 2 was prepared according to the literature procedure. ${ }^{2}$

${ }^{1} \mathrm{H}$ NMR $\left(500 \mathrm{MHz}, \mathrm{CDCl}_{3}\right)$ ठ 7.56-7.52 (m, 1H), 7.47-7.41 (m, 1H), 7.37-7.32 (m, 2H), 0.37 (s, 9H).<smiles>CCC1=NN(c2ccccc2)c2c(C)c3ccccc3c3cccc1c23</smiles>

4-ethyl-7-methyl-6-phenyl-6H-dibenzo[de,g]cinnoline (3): Synthetic method and characterization data of 3 have been reported in our previous publication. ${ }^{1}$ 


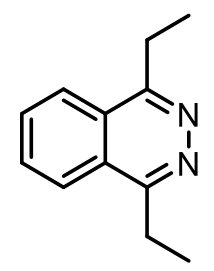

4

1,4-diethylphthalazine (4): A vial was charged with $8.0 \mathrm{mmol}$ of $1(1.10 \mathrm{~g})$ and $4.0 \mathrm{mmol}$ of $2(0.97 \mathrm{~mL})$ in $4.0 \mathrm{~mL}$ of dichloromethane at $24{ }^{\circ} \mathrm{C}$, and $1 \mathrm{M} \mathrm{TBAF}$ in THF $(4.4 \mathrm{mmol}, 4.4 \mathrm{~mL})$ was slowly added to the solution over the course of 20 minutes. After the addition, the solution was concentrated in vacuo, and filtered on the silica gel, and purified by flash column chromatography (hexanes/ethyl acetate 1:3) to afford $4(0.27 \mathrm{~g})$. The data for this compound was previously reported in the literature. ${ }^{3,4}$

Isolated Yield: $37 \%$.

Physical Property: White solid.

TLC: $\mathbf{R}_{\mathbf{f}}=0.17$ (silica gel, $25 \%$ ethyl acetate/hexanes).

${ }^{1} \mathrm{H}$ NMR $\left(500 \mathrm{MHz}, \mathrm{CDCl}_{3}\right)$

$\delta 8.05$ (dd, $2 \mathrm{H}, \mathrm{J}=6.3,3.3 \mathrm{~Hz}$ ), 7.80 (dd, $2 \mathrm{H}, \mathrm{J}=6.3,3.3 \mathrm{~Hz}$ ), 3.30 (q, $4 \mathrm{H}, 7.5 \mathrm{~Hz}$ ), 1.44 (t, $6 \mathrm{H}, 7.5 \mathrm{~Hz}$ ).

${ }^{13} \mathrm{C}$ NMR $\left(125 \mathrm{MHz}, \mathrm{CDCl}_{3}\right)$

$\delta 159.9,131.5,125.3,124.5,26.3,13.1$.

HRMS (ESI) calculated for $\mathrm{C}_{12} \mathrm{H}_{14} \mathrm{~N}_{2} \mathrm{Na}^{+}[\mathrm{M}+\mathrm{Na}]^{+} 209.1049$, found 209.1064.<smiles>CCC1=NN(c2ccccc2)[C@@](CC)(C(Cl)Cl)c2ccccc21</smiles>

rac-5a

$(R)$ - and (S)-1-(dichloromethyl)-1,4-diethyl-2-phenyl-1,2-dihydrophthalazine (rac-5a): A $4 \mathrm{~mL}$ vial was charged with $48 \mu \mathrm{mol}$ of 1,4-diethylphthalazine $4 \quad(9.0 \mathrm{mg}), 480 \mu \mathrm{mol}$ of 2-(trimethylsilyl)phenyl trifluoromethanesulfonate $2(140 \mathrm{mg})$ in $50 \mu \mathrm{L}$ of dichloromethane at $24{ }^{\circ} \mathrm{C}, 1 \mathrm{M}$ TBAF in THF $(530 \mu \mathrm{mol}, 53 \mu \mathrm{L})$ was slowly added to the solution over the course of 5 minutes. After the addition, the solution was concentrated in vacuo, and filtered on the silica gel, and purified by flash column chromatography (ethyl acetate/hexanes $1: 10$ ) to afford rac-5a (2.2 mg).

Isolated Yield: $13 \%$

Physical Property: White solid, m.p. $=111-112^{\circ} \mathrm{C}$.

TLC: $\mathbf{R}_{\mathbf{f}}=0.70$ (silica gel, ethyl acetate/hexanes 1:4).

${ }^{1} \mathrm{H}$ NMR $\left(500 \mathrm{MHz}, \mathrm{CD}_{2} \mathrm{Cl}_{2}\right)$

ठ 7.59-7.54 (m, 1H), 7.54-7.50 (m, 2H), 7.49-7.46 (m, 3H), 7.43-7.37 (m, 2H), 7.29 (tt, 1H, J = 7.4, 0.9 Hz), $5.77(\mathrm{~s}$, $1 \mathrm{H}), 2.79-2.55(\mathrm{~m}, 3 \mathrm{H}), 2.04-1.95(\mathrm{~m}, 1 \mathrm{H}), 1.22(\mathrm{t}, 3 \mathrm{H}, \mathrm{J}=7.5 \mathrm{~Hz}), 1.07(\mathrm{t}, 3 \mathrm{H}, \mathrm{J}=7.2 \mathrm{~Hz})$.

${ }^{13} \mathrm{C}$ NMR $\left(125 \mathrm{MHz}, \mathrm{CD}_{2} \mathrm{Cl}_{2}\right)$ 
$\delta 145.5,142.4,129.2,128.6,128.5,127.9,127.84,127.80,127.0,126.3,123.6,122.7,77.3,69.8,28.2,25.4$, 11.6, 9.9.

IR (neat): 2973, 2929, 2869, 1596, 1492, 1446, 1093, 1034, 753, $699 \mathrm{~cm}^{-1}$.

HRMS (ESI) calculated for $\mathrm{C}_{19} \mathrm{H}_{21} \mathrm{~N}_{2} \mathrm{Cl}_{2}{ }^{+}[\mathrm{M}+\mathrm{H}]^{+} 347.1076$, found 347.1083 .<smiles>[2H]c1ccccc1N1N=C(CC)c2ccccc2[C@@]1(CC)C([2H])([2H])Cl</smiles>

$\operatorname{rac}-\left[\mathrm{D}_{2}\right]-5 \mathrm{a}$

$(R)$ - and (S)-1-(dichloromethyl-d)-1,4-diethyl-2-(phenyl-2-d)-1,2-dihydrophthalazine (rac-[ $\left.\left.\mathrm{D}_{2}\right]-5 \mathrm{a}\right)$ : A vial was charged with $19 \mathrm{mg}(0.10 \mathrm{mmol})$ of 4 and $300 \mathrm{mg}(1.0 \mathrm{mmol})$ of 2 in $100 \mu \mathrm{L}$ of dichloromethane at $24{ }^{\circ} \mathrm{C}$, and $1 \mathrm{M}$ TBAF in THF $(1.1 \mathrm{mmol}, 1.1 \mathrm{~mL})$ was slowly added to the solution over the course of 5 minutes. After the addition, the solution was concentrated in vacuo, and filtered on the silica gel, and purified by flash column chromatography (ethyl acetate/hexanes $1: 10)$ to afford rac-[ $\left[\mathrm{D}_{2}\right]-5 \mathrm{a}(1.2 \mathrm{mg})$.

Isolated Yield: $3 \%$.

Physical Property: White solid, m.p. $=112-113^{\circ} \mathrm{C}$.

TLC: $\mathbf{R}_{\mathbf{f}}=0.70$ (silica gel, ethyl acetate/hexanes 1:4).

${ }^{1} \mathrm{H}$ NMR $\left(500 \mathrm{MHz}, \mathrm{CD}_{2} \mathrm{Cl}_{2}\right)$

ס 7.59-7.54 (m, 1H), 7.54-7.50 (m, 1H), 7.49-7.46 (m, 3H), 7.43-7.37 (m, 2H), $7.29(\mathrm{tt}, 1 \mathrm{H}, \mathrm{J}=7.4,0.9 \mathrm{~Hz}), 2.79-$ $2.55(\mathrm{~m}, 3 \mathrm{H}), 2.04-1.95(\mathrm{~m}, 1 \mathrm{H}), 1.22(\mathrm{t}, 3 \mathrm{H}, \mathrm{J}=7.5 \mathrm{~Hz}), 1.07(\mathrm{t}, 3 \mathrm{H}, \mathrm{J}=7.2 \mathrm{~Hz})$.

HRMS (ESI) calculated for $\mathrm{C}_{19} \mathrm{H}_{18} \mathrm{D}_{2} \mathrm{~N}_{2} \mathrm{Cl}_{2}{ }^{+}[\mathrm{M}+\mathrm{H}]^{+} 349.1202$, found 349.1204.

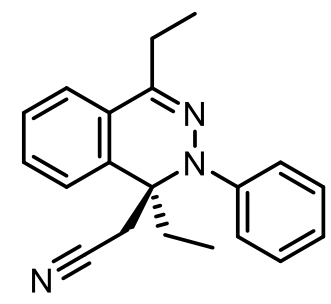

rac-5b

$(R)$ - and (S)-2-(1,4-diethyl-2-phenyl-1,2-dihydrophthalazin-1-yl)acetonitrile (rac-5b), Procedure I (Scheme 2, eq 6): A $4 \mathrm{~mL}$ vial was charged with $48 \mu \mathrm{mol}$ of 1,4-diethylphthalazine $4(9.0 \mathrm{mg}), 480 \mu \mathrm{mol}$ of 2(trimethylsilyl)phenyl trifluoromethanesulfonate $2(140 \mathrm{mg})$ in $50 \mu \mathrm{L}$ of dichloromethane at $24{ }^{\circ} \mathrm{C}, 1 \mathrm{M}$ TBAF in THF $(530 \mu \mathrm{mol}, 530 \mu \mathrm{L})$ was slowly added to the solution over the course of 5 minutes. After the addition, the solution was concentrated in vacuo, and filtered on the silica gel, and purified by flash column chromatography (ethyl acetate/hexanes 1:10) to afford rac-5b (1.2 mg).

$(R)$ - and (S)-2-(1,4-diethyl-2-phenyl-1,2-dihydrophthalazin-1-yl)acetonitrile (rac-5b), Procedure II: A $4.0 \mathrm{~mL}$ vial was charged with $48 \mu \mathrm{mol}$ of 1,4-diethylphthalazine $4(9.0 \mathrm{mg}), 480 \mu \mathrm{mol}$ of 2-(trimethylsilyl)phenyl trifluoromethanesulfonate $2(140 \mathrm{mg}), 530 \mu \mathrm{mol}$ of anhydrous CsF $(81 \mathrm{mg})$ in $50 \mu \mathrm{L}$ of acetonitrile was heated to $80{ }^{\circ} \mathrm{C}$. After 2 hours, the solution was cooled down, concentrated in vacuo and purified by flash column 
chromatography (ethyl acetate/hexanes $1: 10)$ to afford rac-5b $(3.6 \mathrm{mg})$.

Isolated Yield: 8\% (Procedure I), $25 \%$ (Procedure II).

Physical Property: Pale yellow solid, m.p. $=135-136{ }^{\circ} \mathrm{C}$.

TLC: $\mathbf{R}_{\mathbf{f}}=0.38$ (silica gel, ethyl acetate/hexanes 1:4).

${ }^{1} \mathrm{H}$ NMR $\left(500 \mathrm{MHz}, \mathrm{CD}_{2} \mathrm{Cl}_{2}\right)$

ס 7.54-7.40 (m, 7H), 7.39-7.36 (m, 1H), 7.34-7.30 (m, 1H), 2.83-2.68 (m, 4H), 2.10-1.95 (m, 2H), $1.26(\mathrm{t}, 3 \mathrm{H}, \mathrm{J}=$ $7.6 \mathrm{~Hz}), 0.97(\mathrm{t}, 3 \mathrm{H}, \mathrm{J}=7.3 \mathrm{~Hz})$.

${ }^{13} \mathrm{C}$ NMR $\left(125 \mathrm{MHz}, \mathrm{CD}_{2} \mathrm{Cl}_{2}\right)$

ठ 146.1, 146.0, 132.9, 130.1, 128.6, 128.4, 128.2, 126.6, 125.2, 123.3, 117.6, 63.4, 27.7, 25.8, 25.4, 11.6, 8.9.

IR (neat): 2973, 2032, 2877, 1594, 1492, 1472, 1446, 1210, 1119, 756, $702 \mathrm{~cm}^{-1}$.

HRMS (ESI) calculated for $\mathrm{C}_{20} \mathrm{H}_{22} \mathrm{~N}_{3}^{+}[\mathrm{M}+\mathrm{H}]^{+} 304.1808$, found 304.1808 .

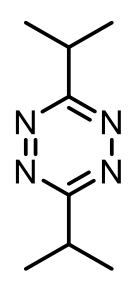

3,6-diisopropyl-1,2,4,5-tetrazine: 3,6-diisopropyl-1,2,4,5-tetrazine was prepared according to the literature procedure from commercially available isobutyronitrile. ${ }^{5}$ The product was purified by flash column chromatography (ethyl acetate/hexanes $=6.25 \%$ ).

Isolated Yield: $56 \%$.

Physical Property: Red oil.

TLC: $\mathbf{R}_{\mathbf{f}}=0.46$ (silica gel, $25 \%$ ethyl acetate/hexanes).

${ }^{1} \mathrm{H}$ NMR $\left(500 \mathrm{MHz}, \mathrm{CDCl}_{3}\right.$ ) $\delta 3.36$ (sep, $2 \mathrm{H}, \mathrm{J}=7.0 \mathrm{~Hz}$ ), 1.25 (d, 12H, J = 7.0 Hz).

${ }^{13} \mathrm{C}$ NMR $\left(125 \mathrm{MHz}, \mathrm{CDCl}_{3}\right) \delta 173.4,33.9,21.0$.

IR (neat): 2973, 2934, 2877, 1472, 1461, 1383, 1365, 1336, 1286, 1250, 1072, 899, $883 \mathrm{~cm}^{-1}$.

HRMS (ESI) calculated for $\mathrm{C}_{8} \mathrm{H}_{14} \mathrm{~N}_{4}^{+}[\mathrm{M}]^{+}$166.1213, found 166.1222.

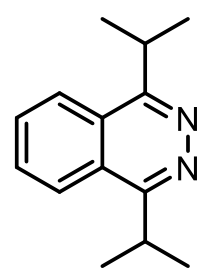

6

1,4-diisopropylphthalazine (6): A vial was charged with $0.117 \mathrm{mmol}$ of 3,6-diisopropyl-1,2,4,5-tetrazine (19.5 $\mathrm{mg})$ and $1.17 \mathrm{mmol}$ of $2(350 \mathrm{mg})$ in $0.1 \mathrm{~mL}$ of dichloromethane at $24{ }^{\circ} \mathrm{C}$, and $1 \mathrm{M}$ TBAF in THF $(1.30 \mathrm{mmol}, 1.30$ $\mathrm{mL}$ ) was slowly added to the solution over the course of 5 minutes. After the addition, the solution was concentrated in vacuo, and filtered on the silica gel, and purified by flash column chromatography (hexanes/ethyl acetate $1: 3)$ to afford $6(18.6 \mathrm{mg})$. 
Isolated Yield: $74 \%$.

Physical Property: White solid, m.p. $=85-86^{\circ} \mathrm{C}$.

TLC: $\mathbf{R}_{\mathbf{f}}=0.19$ (silica gel, ethyl acetate/hexanes 1:4).

${ }^{1} \mathrm{H}$ NMR $\left(500 \mathrm{MHz}, \mathrm{CDCl}_{3}\right)$

$\delta 8.18$ (dd, $2 \mathrm{H}, \mathrm{J}=6.3,3.3 \mathrm{~Hz}$ ), $7.86(\mathrm{dd}, 2 \mathrm{H}, \mathrm{J}=6.3,3.3 \mathrm{~Hz}$ ), $3.86(\operatorname{sep}, 2 \mathrm{H}, 6.8 \mathrm{~Hz}), 1.53(\mathrm{~d}, 12 \mathrm{H}, 6.8 \mathrm{~Hz})$.

${ }^{13} \mathrm{C}$ NMR $\left(125 \mathrm{MHz}, \mathrm{CDCl}_{3}\right)$

$\delta 162.5,131.3,125.0,124.3,30.2,22.0$.

IR (neat): 2968, 2930, 2873, 1540, 1566, 1472, 1457, 1386, 1264, 1087, 1035, 991, 774, 735, 703, $668 \mathrm{~cm}^{-1}$.

HRMS (ESI) calculated for $\mathrm{C}_{22} \mathrm{H}_{16} \mathrm{~N}_{2}^{+}[\mathrm{M}+\mathrm{H}]^{+} 215.1543$, found 215.1554 .

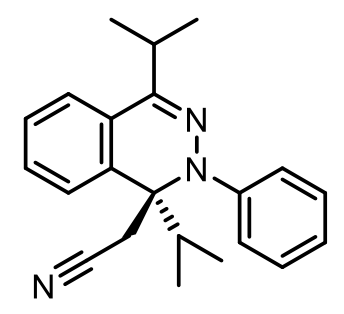

rac-7

(R)- and (S)-2-(1,4-diisopropyl-2-phenyl-1,2-dihydrophthalazin-1-yl)acetonitrile (rac-7): A $4 \mathrm{~mL}$ vial was charged with $0.13 \mathrm{mmol}$ of 1,4-diisopropylphthalazine $6(28 \mathrm{mg}), 1.3 \mathrm{mmol}$ of 2-(trimethylsilyl)phenyl trifluoromethanesulfonate $2(390 \mathrm{mg}), 1 \mathrm{M}$ TBAF in THF $(1.4 \mathrm{mmol}, 1.4 \mathrm{~mL})$ in $50 \mu \mathrm{L}$ of dichloromethane was heated to $80^{\circ} \mathrm{C}$. After 2 hours, the solution was cooled down, concentrated in vacuo and purified by flash column chromatography (ethyl acetate/hexanes $1: 10)$ to afford rac-7 $(0.60 \mathrm{mg})$.

Isolated Yield: $1 \%$.

Physical Property: White solid, m.p. $=140-141^{\circ} \mathrm{C}$.

TLC: $\mathbf{R}_{\mathbf{f}}=0.38$ (silica gel, ethyl acetate/hexanes 1:4).

${ }^{1} \mathrm{H}$ NMR $\left(500 \mathrm{MHz}, \mathrm{CD}_{2} \mathrm{Cl}_{2}\right)$

ठ 7.60-7.40 (m, 7H), 7.35-7.28 (m, 1H), 7.24-7.18 (m, 1H), 3.37 (d, 1H, J = 17.6 Hz), 3.28-3.18 (m, 1H), $2.85(\mathrm{~d}$, $1 \mathrm{H}, \mathrm{J}=17.6 \mathrm{~Hz}), 2.19-2.09(\mathrm{~m}, 1 \mathrm{H}), 1.25-1.21(\mathrm{~m}, 6 \mathrm{H}), 0.90(\mathrm{~d}, 3 \mathrm{H}, \mathrm{J}=6.8 \mathrm{~Hz}), 0.74(\mathrm{~d}, 3 \mathrm{H}, \mathrm{J}=6.8 \mathrm{~Hz})$.

${ }^{13} \mathrm{C}$ NMR $\left(125 \mathrm{MHz}, \mathrm{CD}_{2} \mathrm{Cl}_{2}\right)$

$\delta 146.5,146.2,130.2,129.4,128.7,128.5,128.1,126.4,126.0,125.7,122.8,118.1,66.6,37.0,29.1,27.6,21.3$, 19.7, 19.2, 17.6.

IR (neat): 2960, 2921, 2849, 1262, 1096, 1028, $803 \mathrm{~cm}^{-1}$.

HRMS (ESI) calculated for $\mathrm{C}_{22} \mathrm{H}_{26} \mathrm{~N}_{3}^{+}[\mathrm{M}+\mathrm{H}]^{+} 332.2121$, found 332.2121. 
Crossover Experiment in Scheme 2.<smiles>CCc1nnc(CC)c2ccccc12</smiles>

4<smiles>CCOc1ccccc1C</smiles>

2

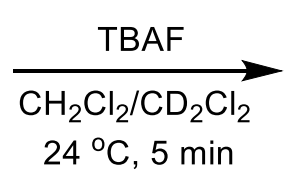<smiles>CCC1=NN(c2ccccc2)[C@@](CC)(C(Cl)Cl)c2ccccc21</smiles>

rac-5a<smiles>[2H]C1=[C+]C=CC=C1N1N=C(CC)c2ccccc2[C@@]1(CC)C([2H])(Cl)Cl</smiles>

rac-[D2]-5a

Each vial was charged with $0.10 \mathrm{mmol}$ of phthalazine $4(19 \mathrm{mg}$ ) and $1.0 \mathrm{mmol}$ of 2-(trimethylsilyl)phenyl trifluoromethanesulfonate $2(300 \mathrm{mg})$ in $100 \mu \mathrm{L}$ of $\mathrm{CH}_{2} \mathrm{Cl}_{2}, \mathrm{CD}_{2} \mathrm{Cl}_{2}, \mathrm{CH}_{2} \mathrm{Cl}_{2} / \mathrm{CD}_{2} \mathrm{Cl}_{2}(1: 1)$, and $\mathrm{CCl}_{4}$ at $24{ }^{\circ} \mathrm{C}$, and 1 $\mathrm{M}$ TBAF in THF $(1.1 \mathrm{mmol}, 1.1 \mathrm{~mL})$ was slowly added to the solution over the course of 5 minutes. After the addition, the solution was concentrated in vacuo, and filtered on the silica gel, and purified by flash column chromatography (ethyl acetate/hexanes $1: 10$ to straight ethyl acetate) to afford $\mathbf{3}, \mathbf{4}$, and rac-5a (or rac-[ $\left.\mathrm{D}_{2}\right]-\mathbf{5 a}$ ).

Crossover Experiment in Scheme 4 (eq 7).<smiles>CCc1nnc(CC)c2ccccc12</smiles>

4

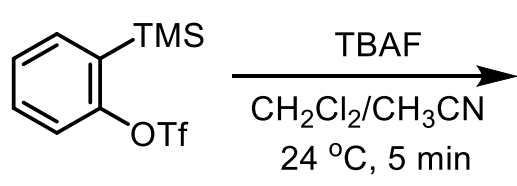

2<smiles>CCC1=NN(c2ccccc2)[C@@](CC)(C(Cl)Cl)c2ccccc21</smiles>

rac-5a<smiles>CCC1=NN(c2ccccc2)[C@](CC)(CC#N)c2ccccc21</smiles>

rac-5b

Each vial was charged with $10 \mu \mathrm{mol}$ of phthalazine $4(1.9 \mathrm{mg})$ and $100 \mu \mathrm{mol}$ of 2-(trimethylsilyl)phenyl trifluoromethanesulfonate $2(30 \mathrm{mg})$ in $\mathrm{CH}_{3} \mathrm{CN}$ and $\mathrm{CH}_{2} \mathrm{Cl}_{2}$ in different molar ratios (total $5.0 \mathrm{mmol}$ ) at $24^{\circ} \mathrm{C}$, and 1 M TBAF in THF $(110 \mu \mathrm{mol}, 110 \mu \mathrm{L})$ was slowly added to each solution over the course of 5 minutes. After the addition, the solutions and 9,10-diphenylanthracene as an internal standard were directly subjected to HPLC for analysis. 


\section{References}

1) Suh, S.-E.; Barros, S. A.; Chenoweth, D. M. Chem. Sci. 2015, 6, 5128.

2) Shaibu, B. S.; Kawade, R. K.; Liu, R.-S. Org. Biomol. Chem. 2012, 10, 6834.

3) Hayashi, E.; linuma, M.; Utsunomiya, I.; lijima, C.; Oishi, E.; Higashino, T. Chem. Pharm. Bull. 1977, 25, 579.

4) Stephenson, L.; Walker, T.; Warburton, W. K.; Webb, G. B. J. Chem. Soc. 1962, 1282.

5) Yang, J.; Karver, M. R.; Li, W.; Sahu, S.; Devaraj, N. K. Angew. Chem. Int. Ed. 2012, 51, 5222. 
${ }^{1} \mathrm{H}$ NMR spectrum of 2 in $\mathrm{CDCl}_{3}(500 \mathrm{MHz})$.

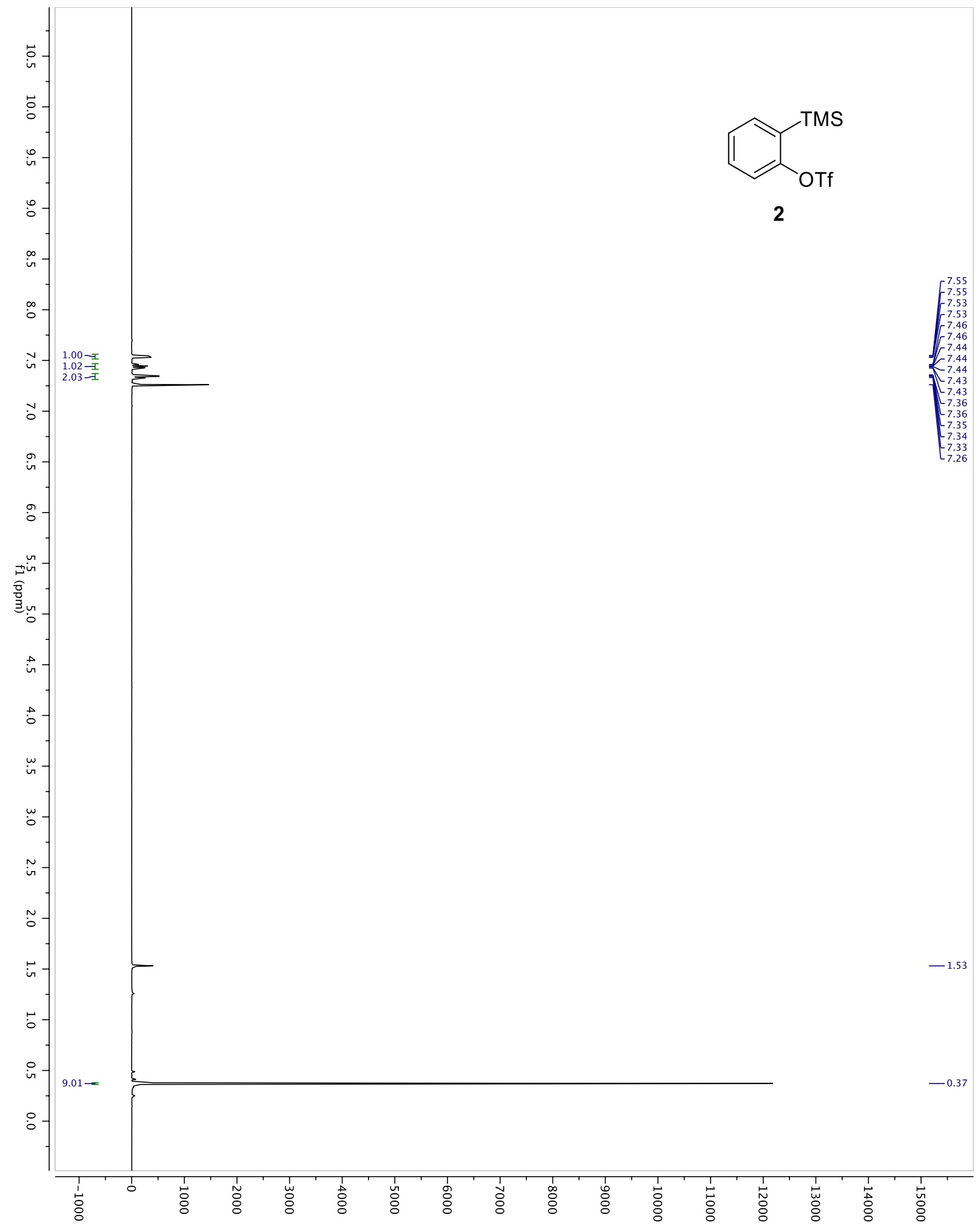


${ }^{1} \mathrm{H}$ NMR spectrum of 4 in $\mathrm{CDCl}_{3}(500 \mathrm{MHz})$.

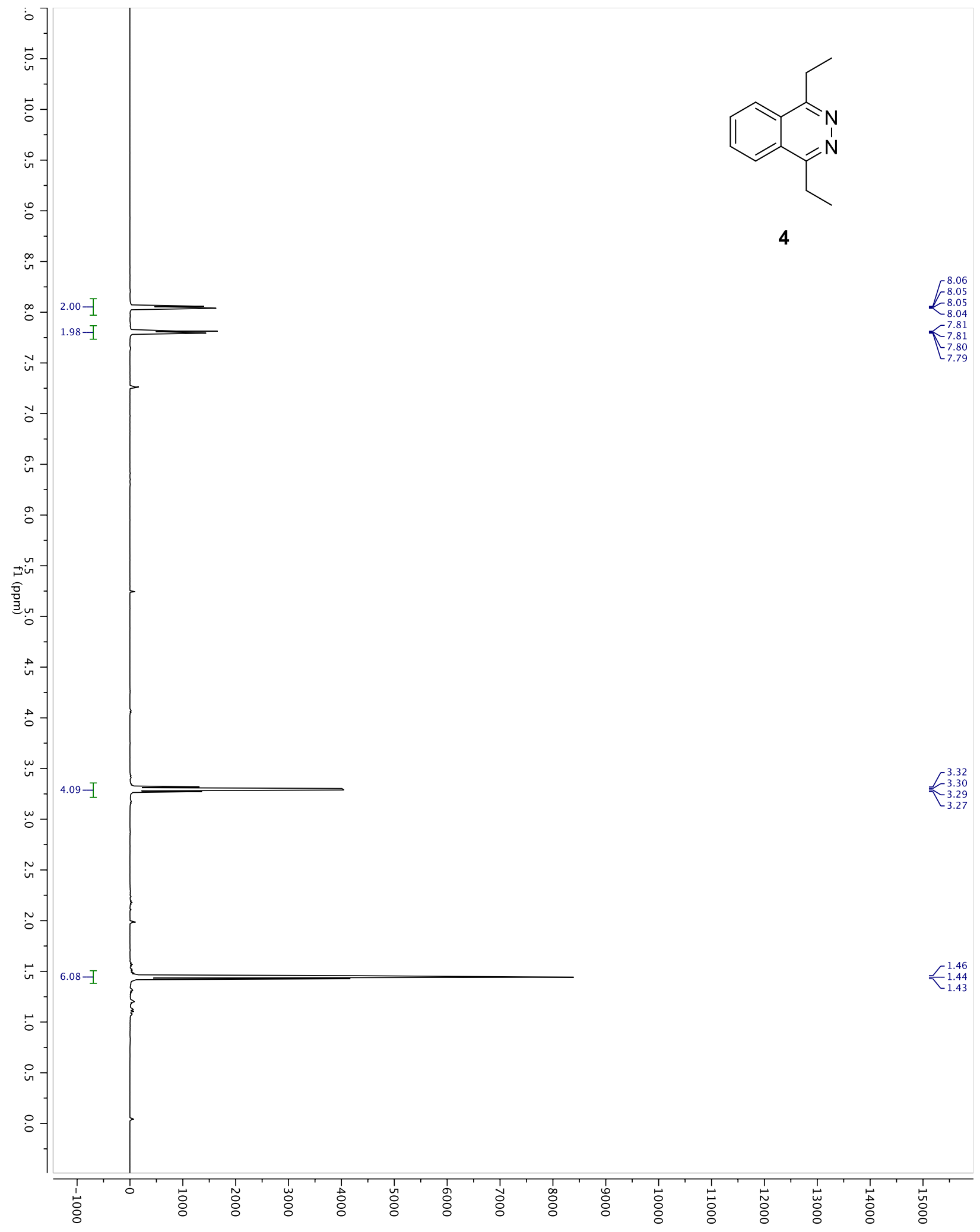


${ }^{13} \mathrm{C}$ NMR spectrum of 4 in $\mathrm{CDCl}_{3}(125 \mathrm{MHz})$.

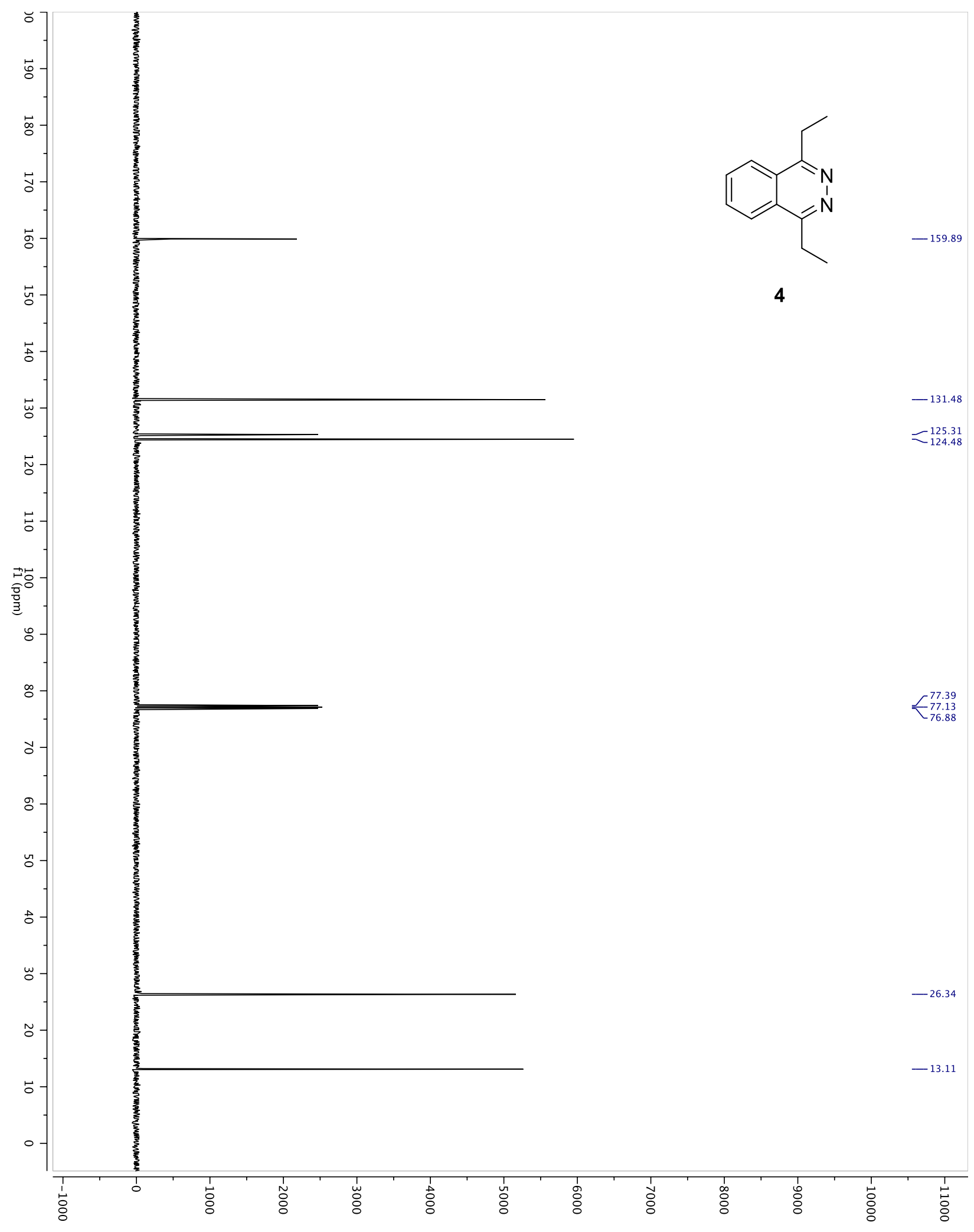

S11 
${ }^{1} \mathrm{H}$ NMR spectrum of rac-5a in $\mathrm{CD}_{2} \mathrm{Cl}_{2}(500 \mathrm{MHz})$.

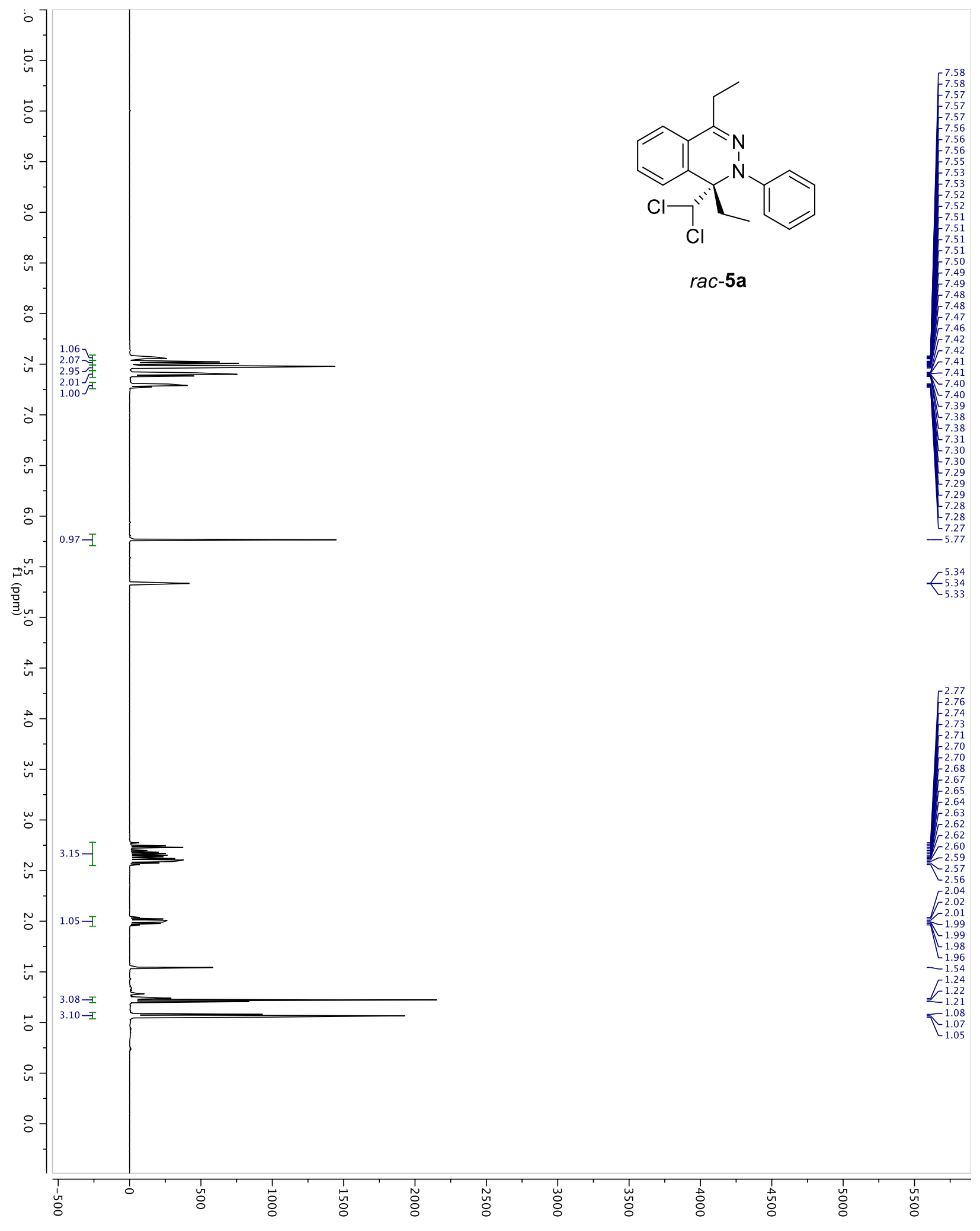


${ }^{13} \mathrm{C}$ NMR spectrum of rac-5a in $\mathrm{CD}_{2} \mathrm{Cl}_{2}(125 \mathrm{MHz})$.

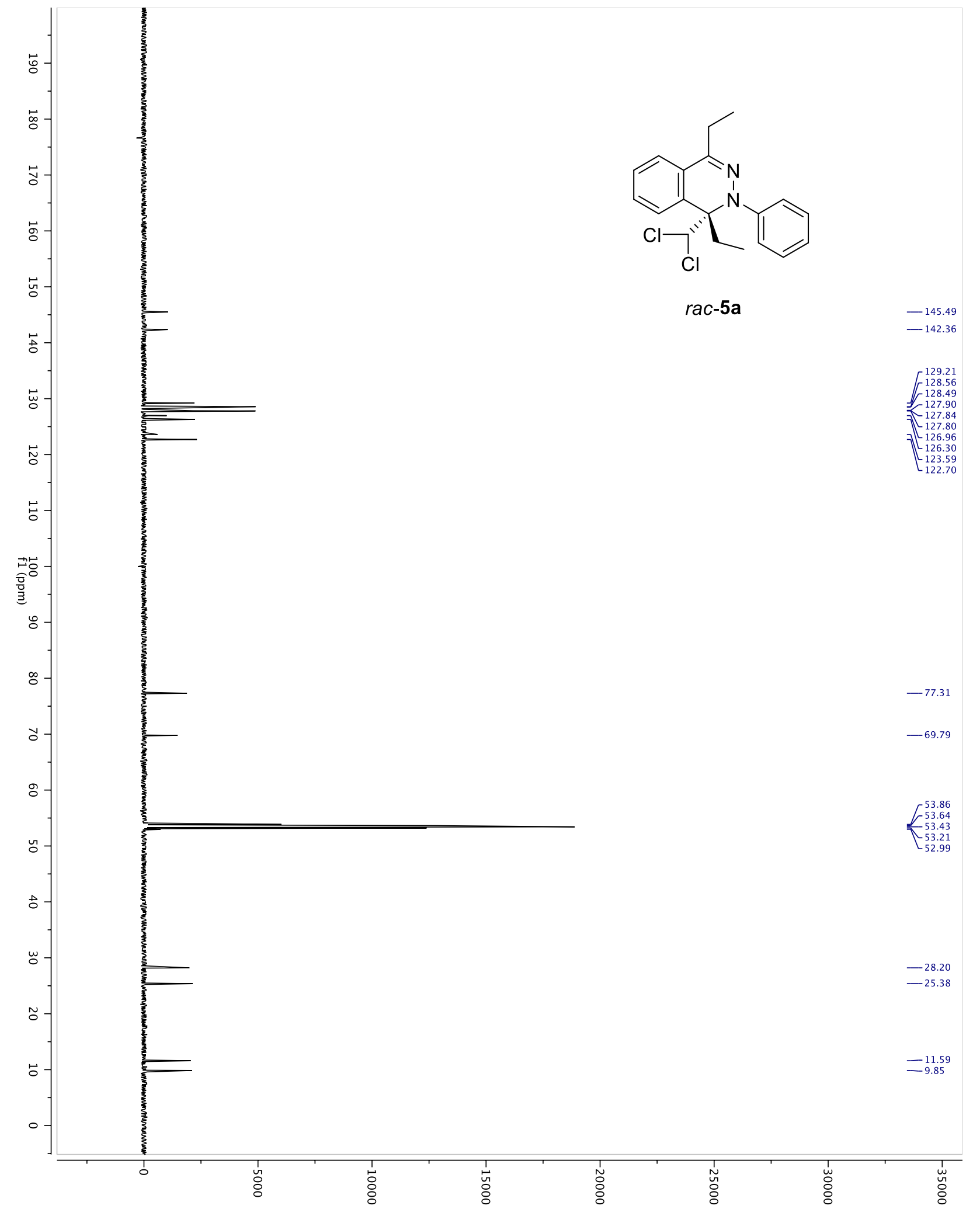


$\mathrm{HSQC}$ spectrum of rac-5a in $\mathrm{CD}_{2} \mathrm{Cl}_{2}$.

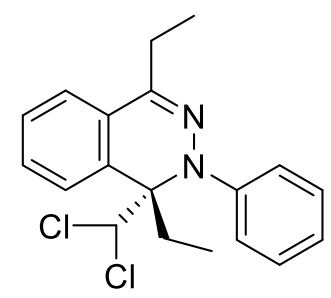

rac-5a

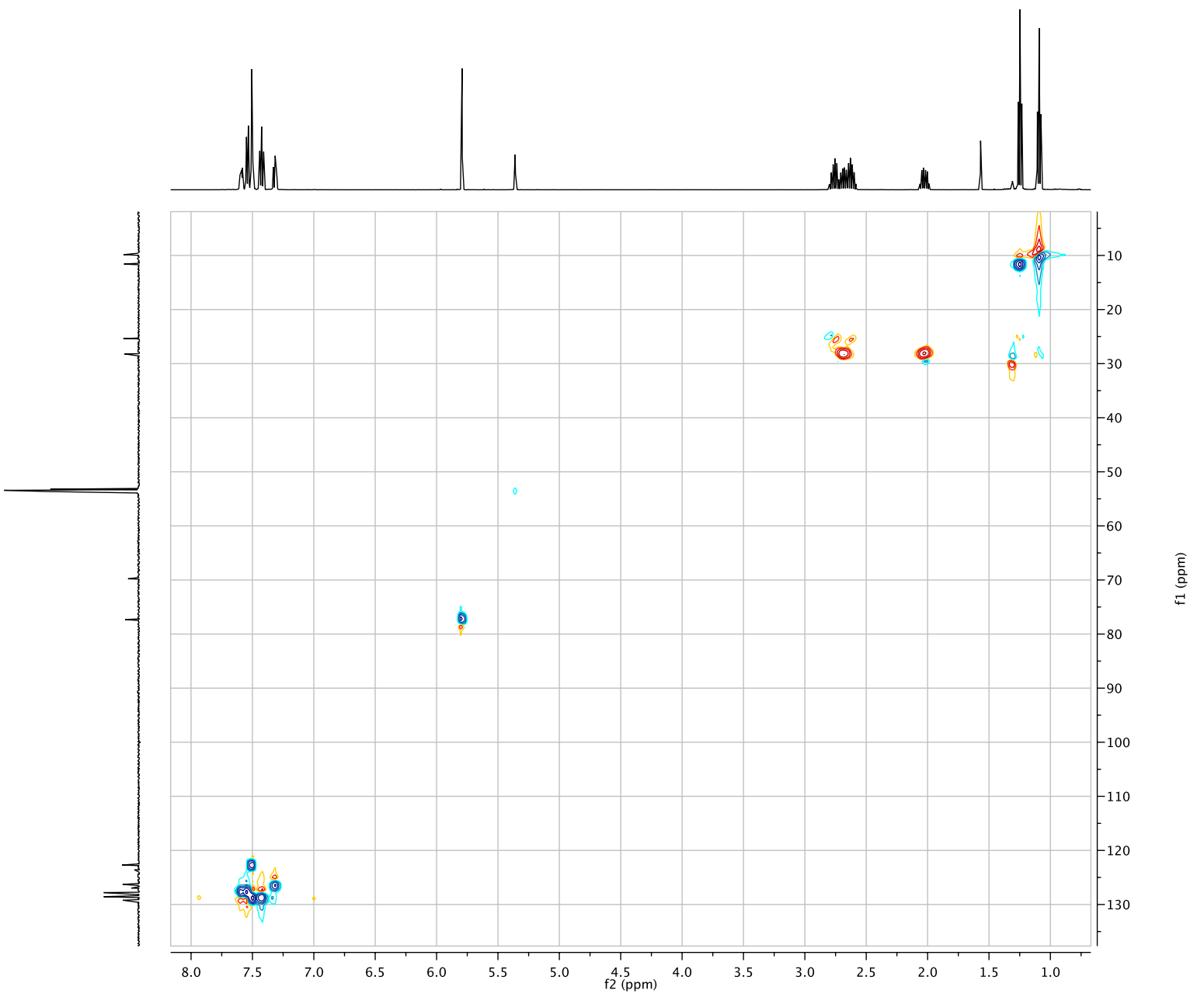


HMBC spectrum of rac-5a in $\mathrm{CD}_{2} \mathrm{Cl}_{2}$.

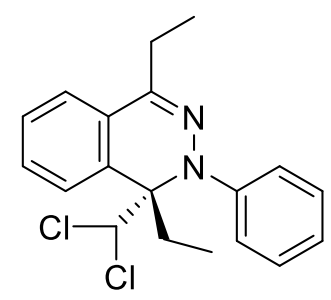

rac-5a

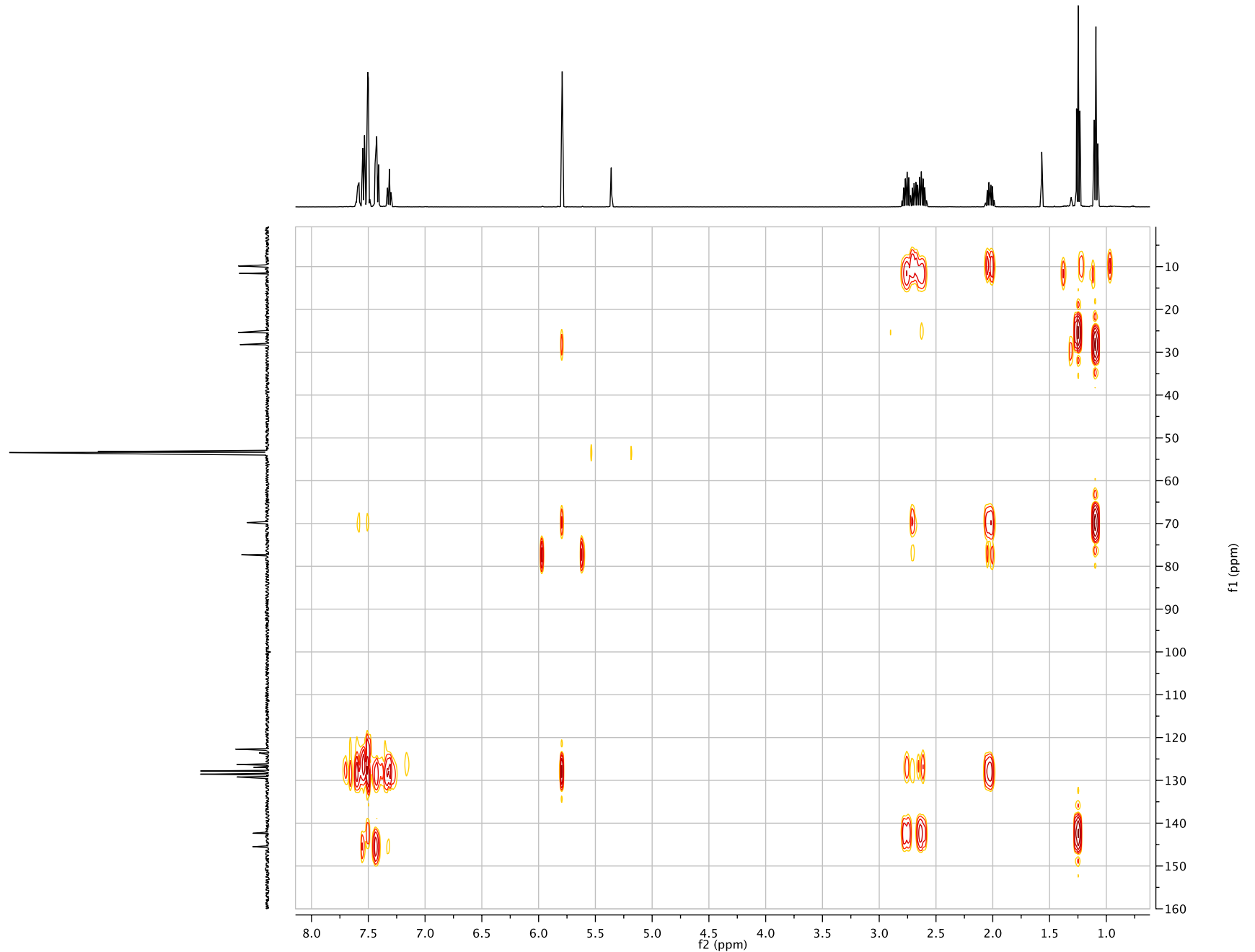


${ }^{1} \mathrm{H}$ NMR spectrum of rac- $\left[\mathrm{D}_{2}\right]-5 \mathrm{a}$ in $\mathrm{CD}_{2} \mathrm{Cl}_{2}(500 \mathrm{MHz})$.

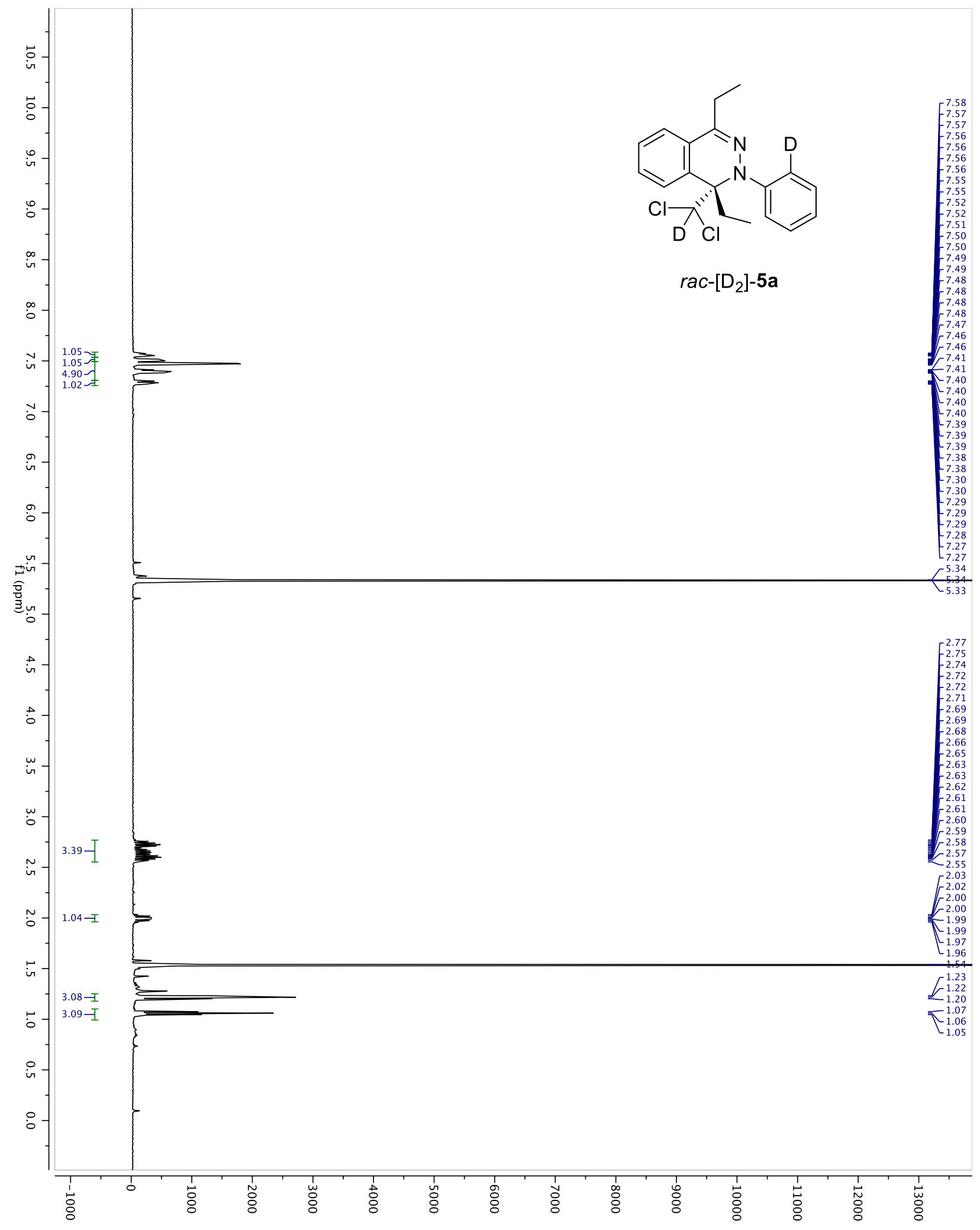


${ }^{1} \mathrm{H}$ NMR spectrum of rac-5b in $\mathrm{CD}_{2} \mathrm{Cl}_{2}(500 \mathrm{MHz})$.

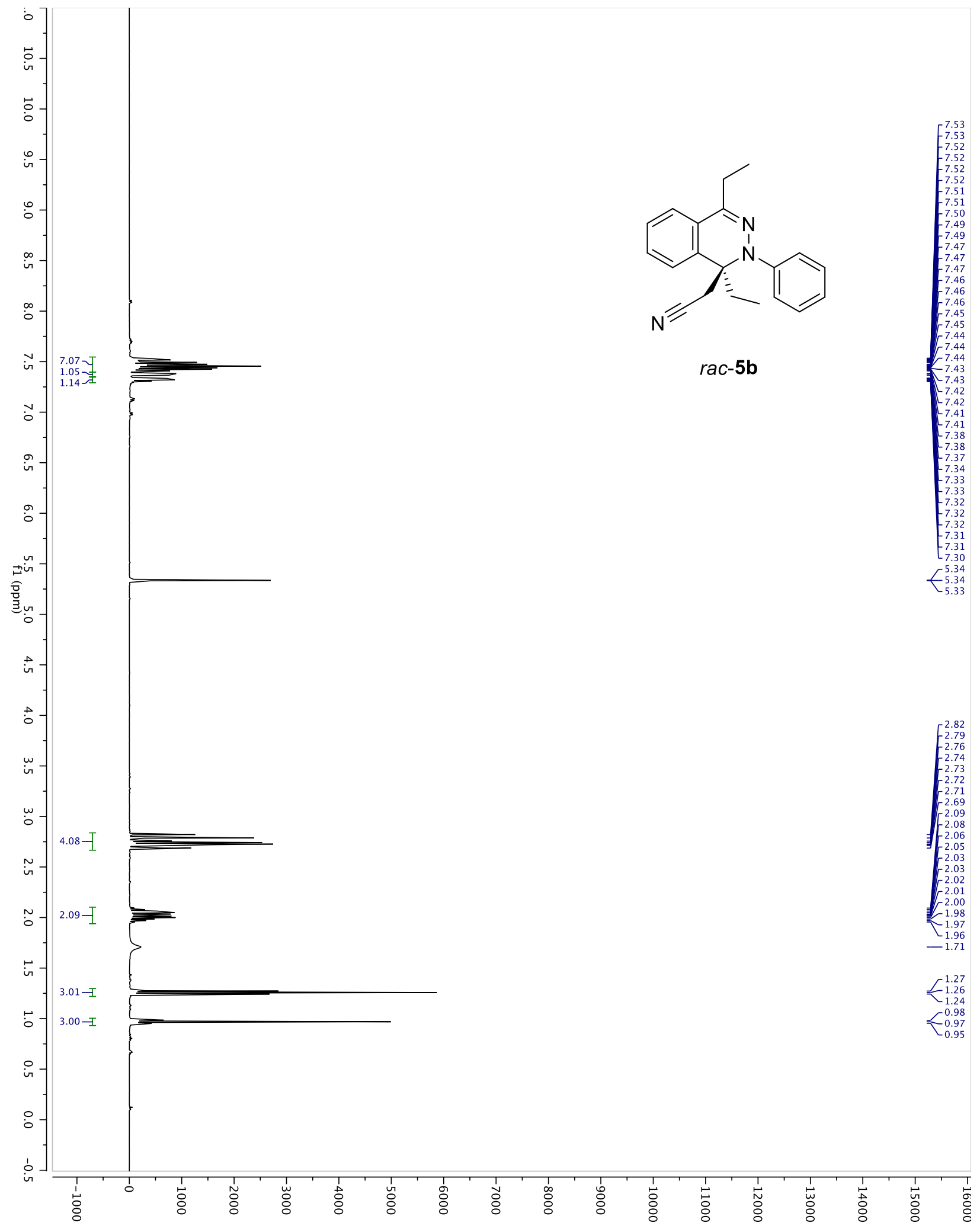


${ }^{13} \mathrm{C}$ NMR spectrum of rac-5b in $\mathrm{CD}_{2} \mathrm{Cl}_{2}(125 \mathrm{MHz})$.

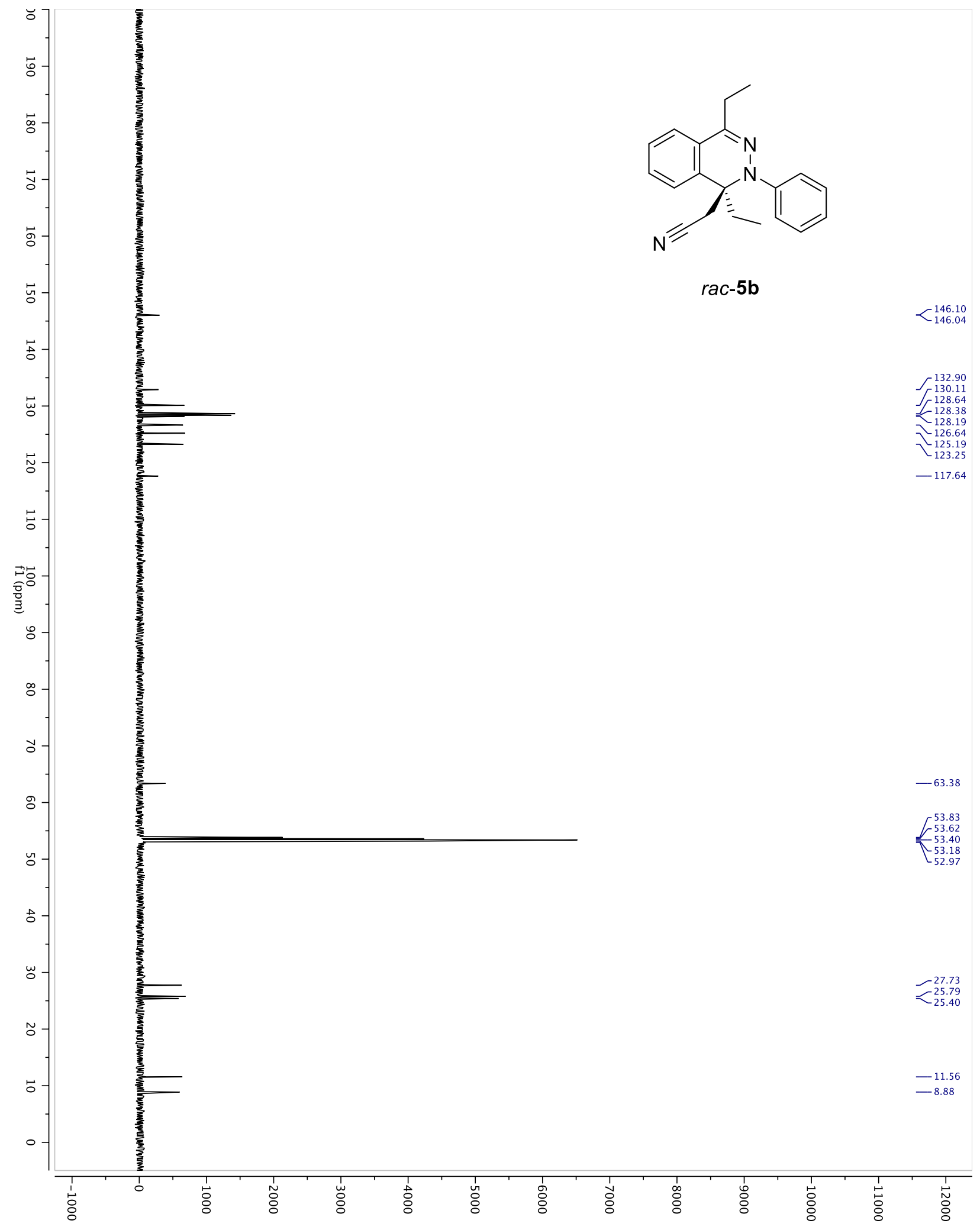


$\mathrm{HMBC}$ spectrum of rac-5b in $\mathrm{CD}_{2} \mathrm{Cl}_{2}$.

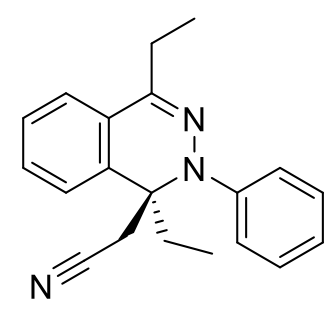

rac-5b

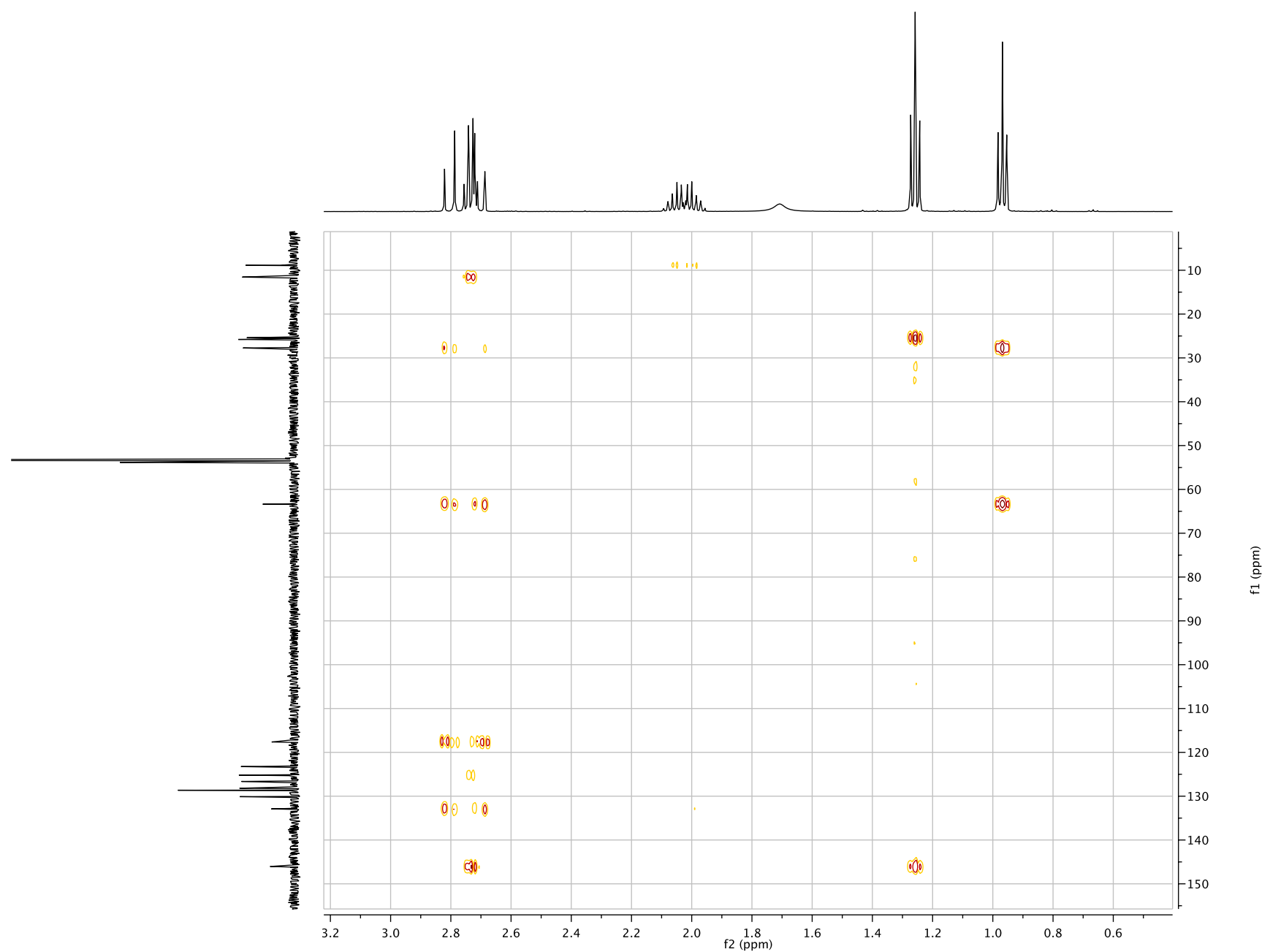


${ }^{1} \mathrm{H}$ NMR spectrum of 3,6-diisopropyl-1,2,4,5-tetrazine in $\mathrm{CDCl}_{3}(500 \mathrm{MHz})$.

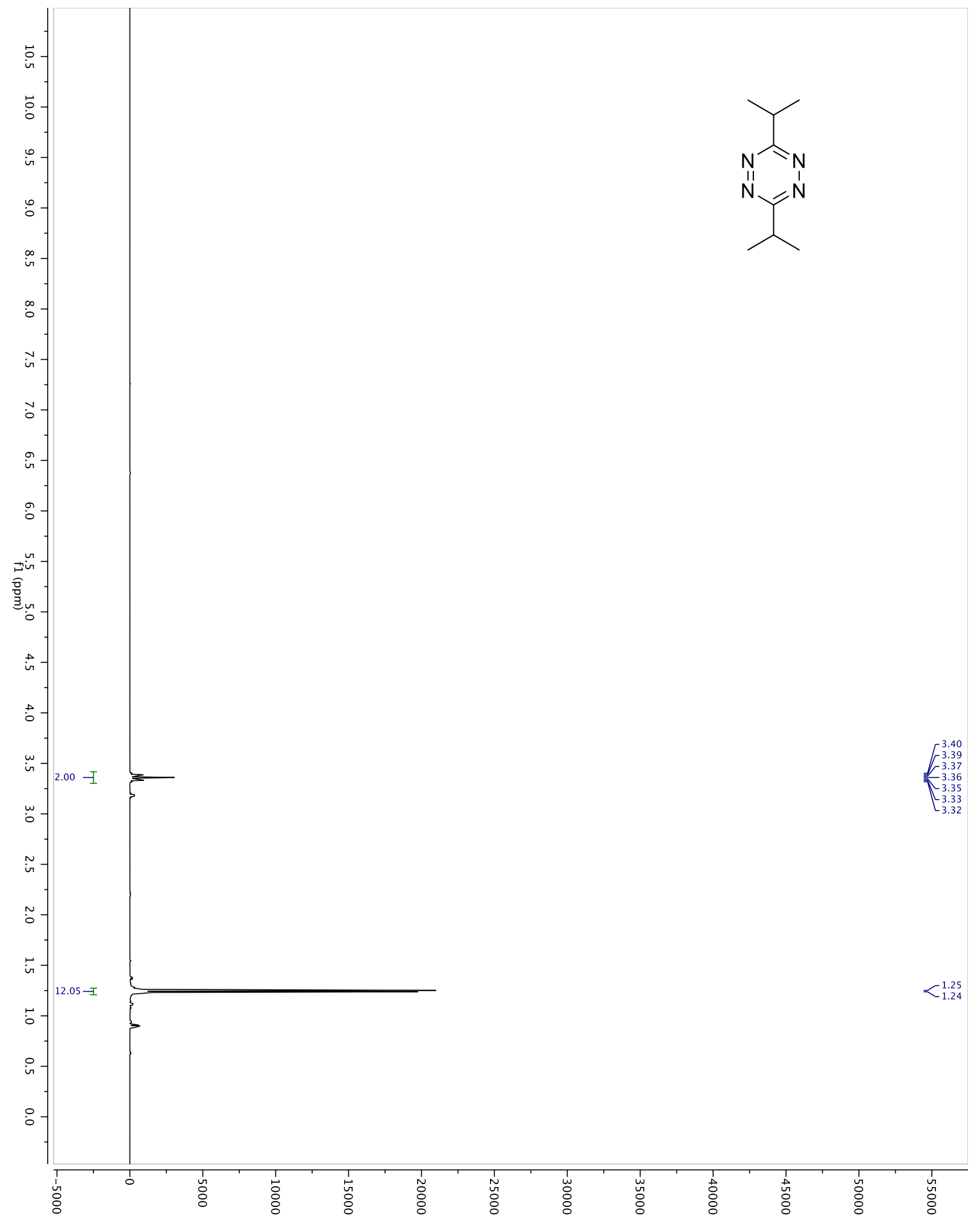


${ }^{13} \mathrm{C}$ NMR spectrum of 3,6-diisopropyl-1,2,4,5-tetrazine in $\mathrm{CDCl}_{3}(125 \mathrm{MHz})$.

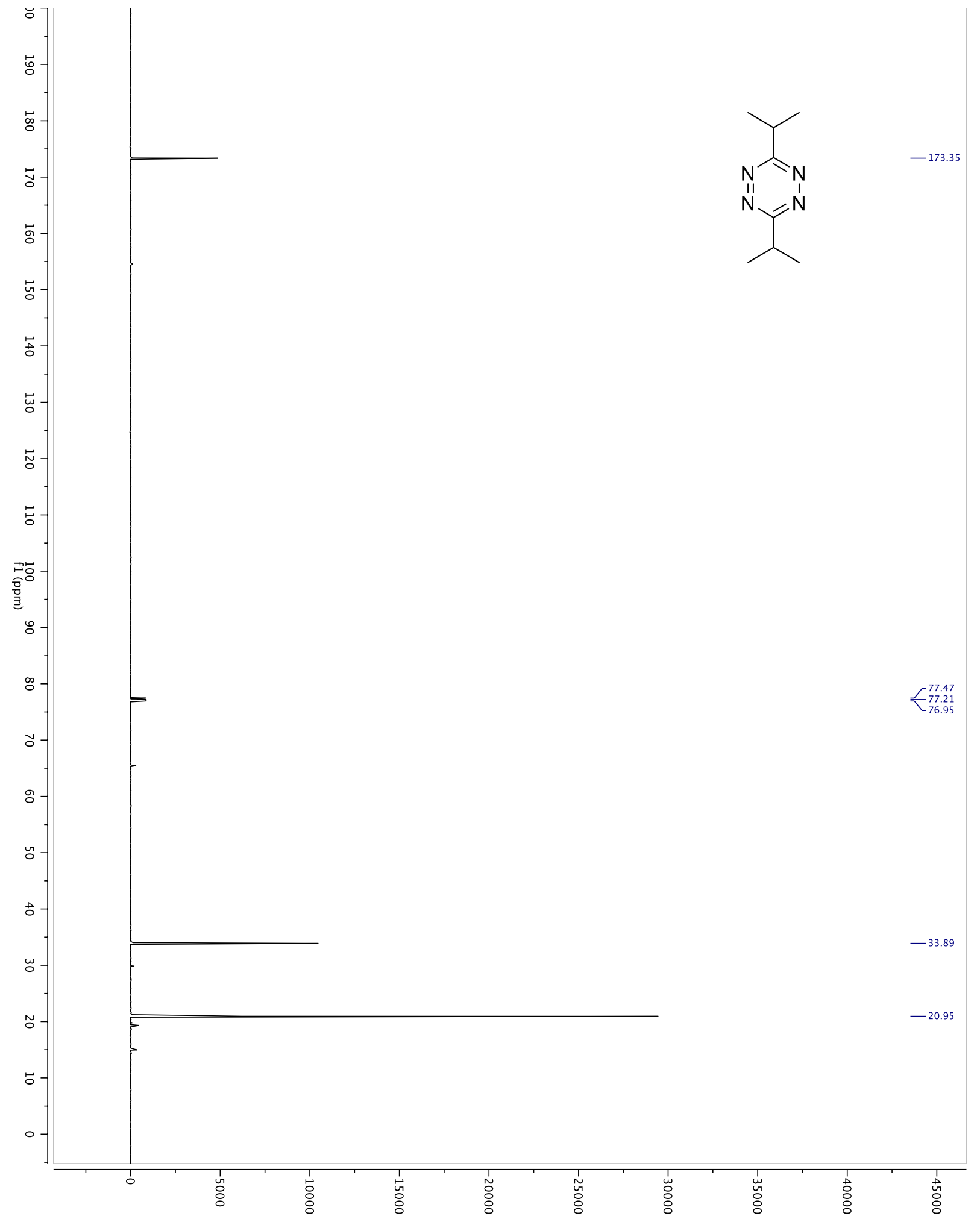


${ }^{1} \mathrm{H}$ NMR spectrum of 6 in $\mathrm{CDCl}_{3}(500 \mathrm{MHz})$.

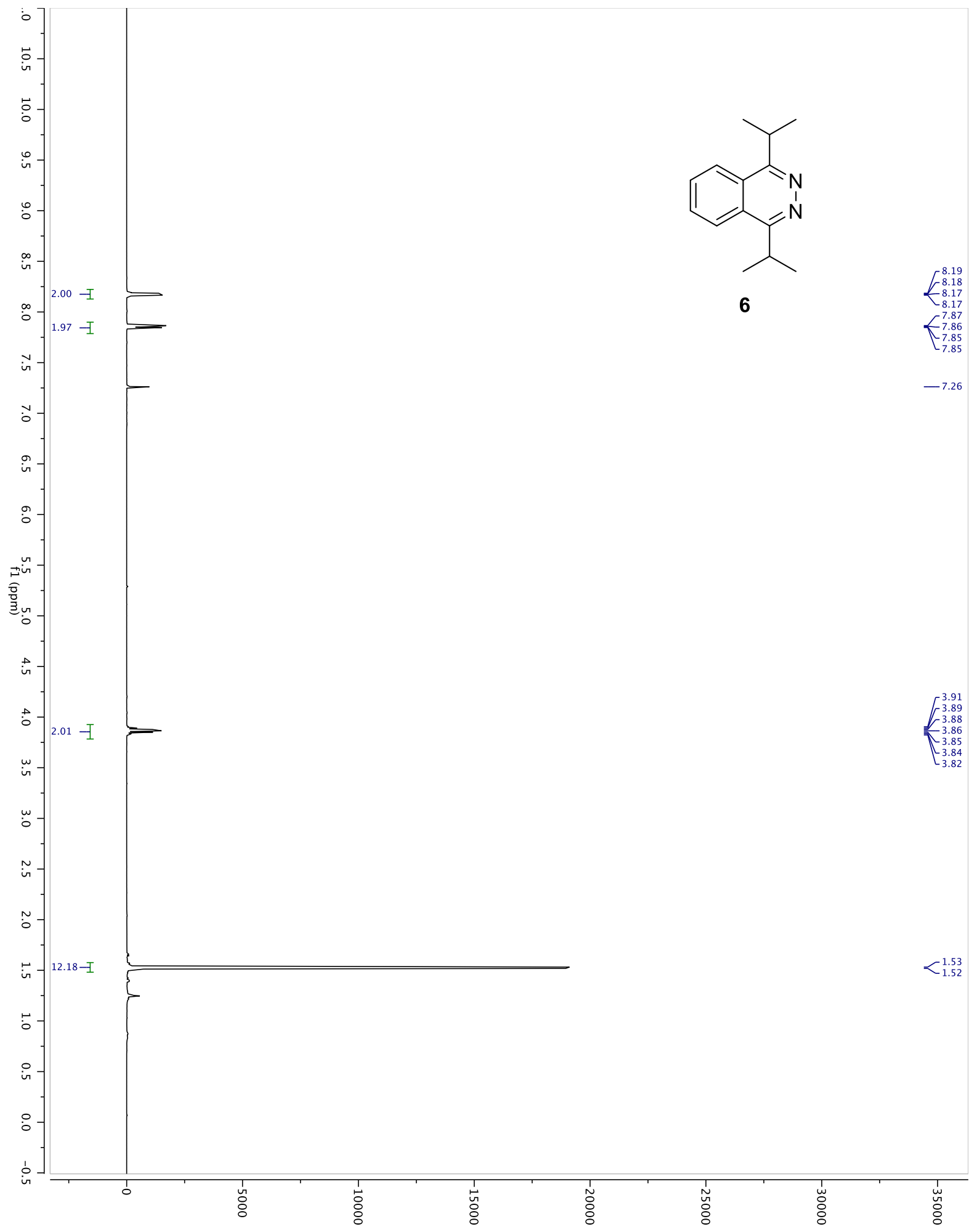


${ }^{13} \mathrm{C}$ NMR spectrum of $4 \mathrm{c}$ in $\mathrm{CDCl}_{3}(125 \mathrm{MHz})$.

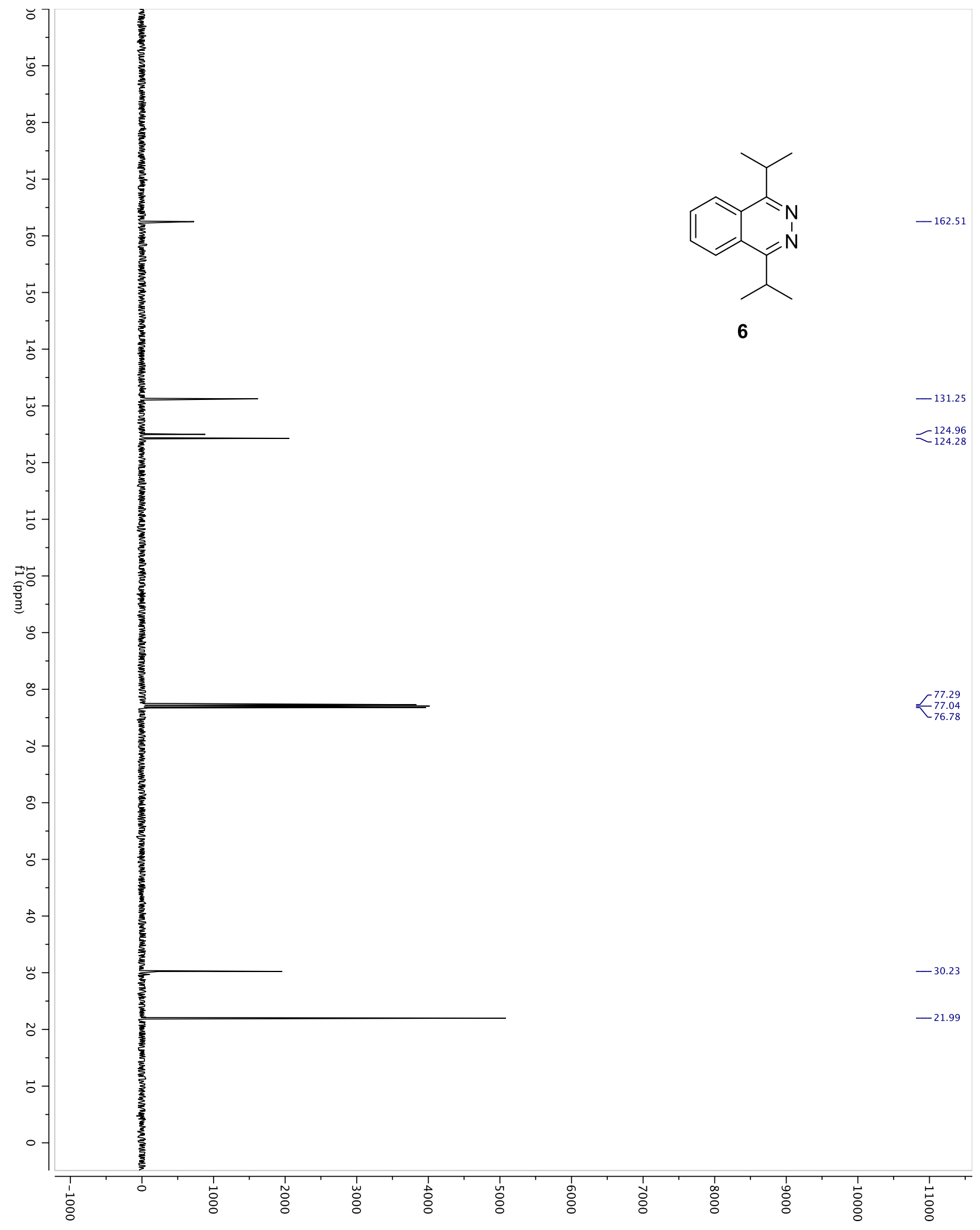


${ }^{1} \mathrm{H}$ NMR spectrum of rac-7 in $\mathrm{CD}_{2} \mathrm{Cl}_{2}(500 \mathrm{MHz})$.

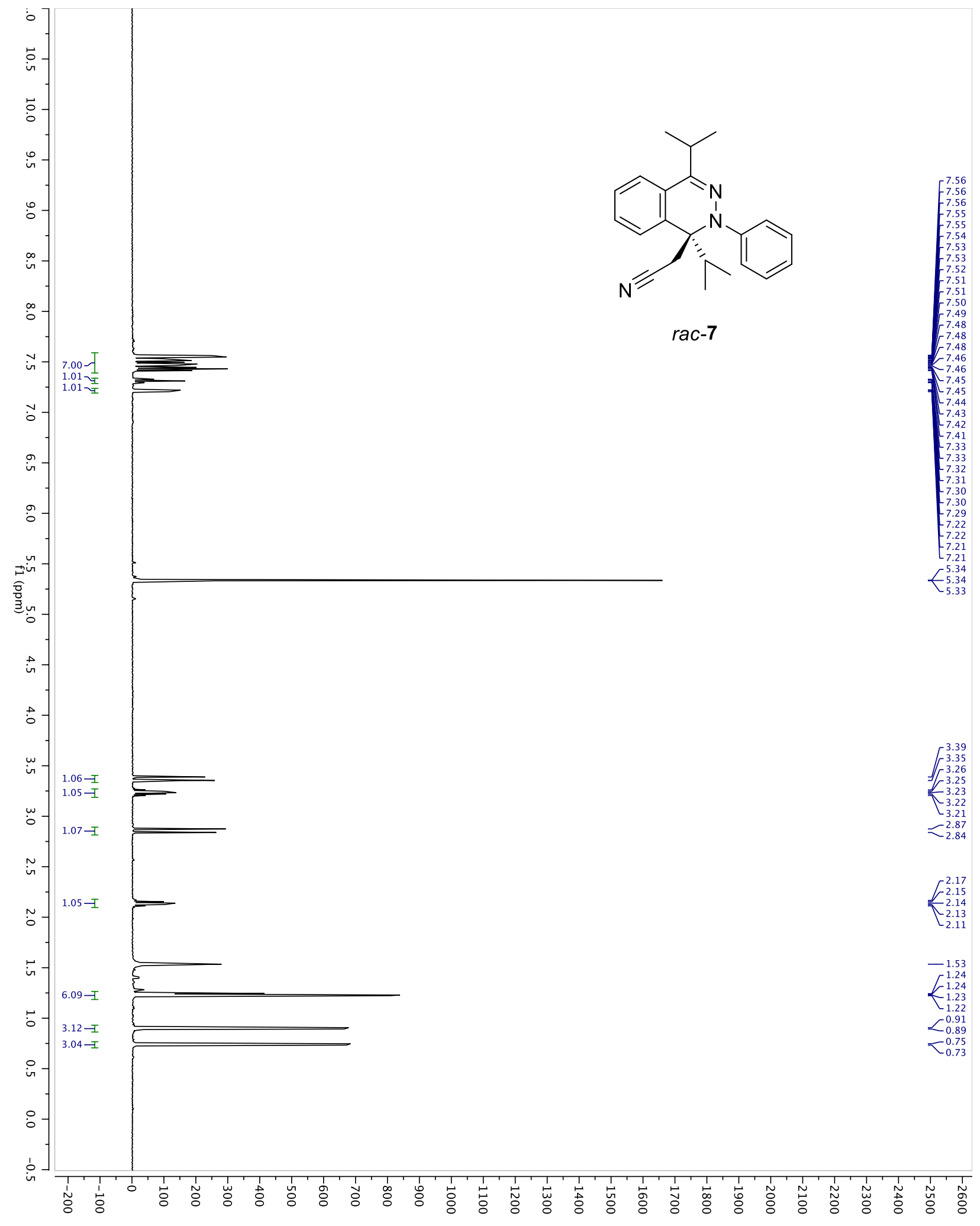


${ }^{13} \mathrm{C}$ NMR spectrum of rac- $6 \mathrm{c}$ in $\mathrm{CD}_{2} \mathrm{Cl}_{2}(125 \mathrm{MHz})$.

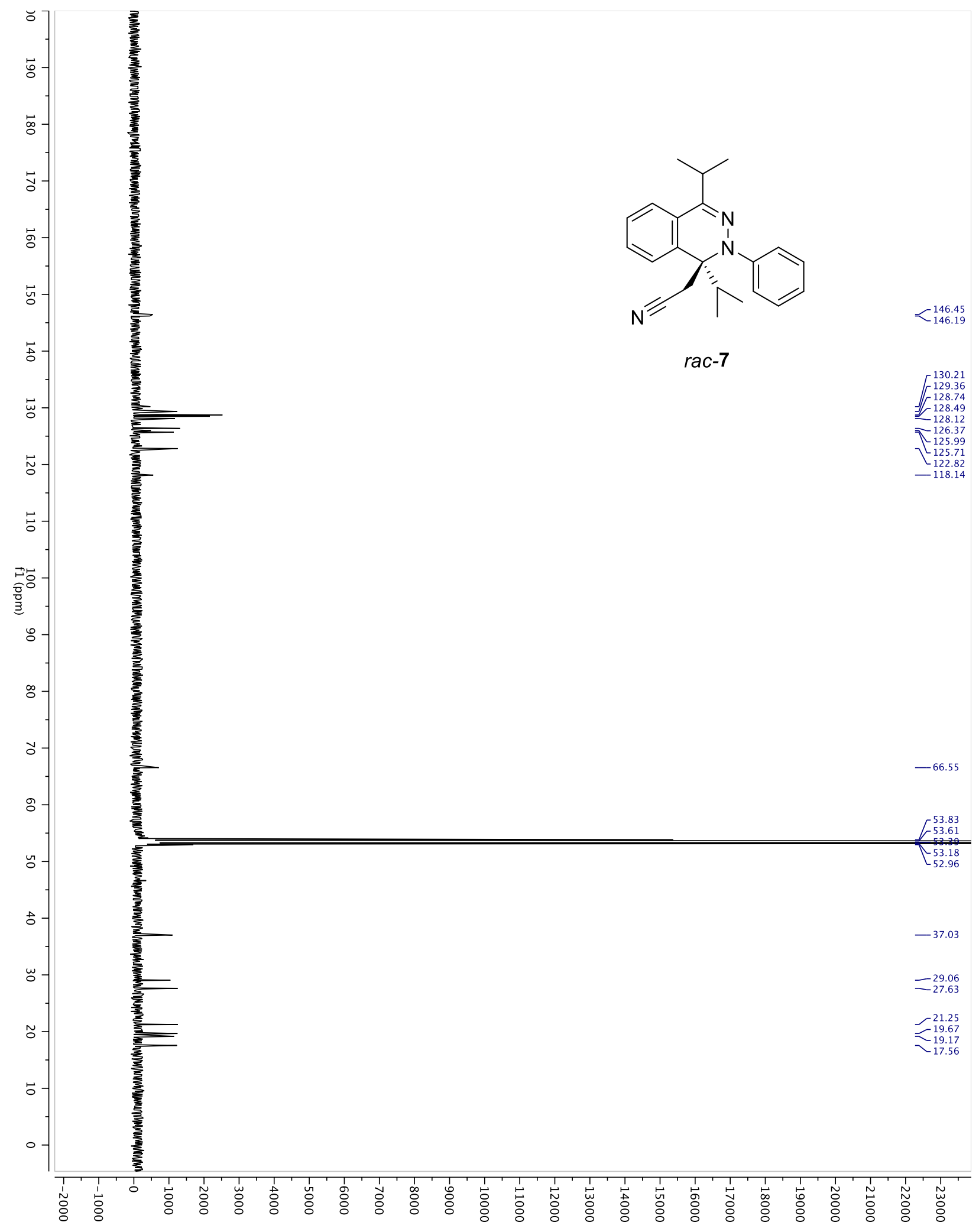


CCDC Number of X-ray crystal structures of $\mathbf{5 a}$ and $\mathbf{5 b}$.

$5 a$

Summary of Data CCDC 1425956

Compound Name:

Formula: $\mathrm{C} 19 \mathrm{H} 20 \mathrm{Cl} 2 \mathrm{~N} 2,() \mathrm{n},(\mathrm{C} 1) \mathrm{n}, 0.85(\mathrm{H} 1 \mathrm{Cl} 1), 0.15(\mathrm{Cl} 1)$

Unit Cell Parameters: a 8.5618(10) b 8.6657(9) c 22.783(3) P212121

$5 b$

Summary of Data CCDC 1425957

Compound Name:

Formula: $\mathrm{C} 20 \mathrm{H} 21 \mathrm{~N} 3$

Unit Cell Parameters: a 7.1149(3) b 26.5631(11) c 8.5150(4) P21 
Crystal data and structure refinement for $\mathbf{5 a}$.

\begin{tabular}{|c|c|}
\hline Empirical formula & $\mathrm{C}_{19} \mathrm{H}_{20} \mathrm{~N}_{2} \mathrm{Cl}_{2}$ \\
\hline Formula weight & 347.27 \\
\hline Temperature & $100(1) \mathrm{K}$ \\
\hline Wavelength & $0.71073 \AA$ \\
\hline Crystal system & orthorhombic \\
\hline Space group & $\mathrm{P} 2{ }_{1}{ }_{1}{ }_{2}{ }_{1}$ \\
\hline \multicolumn{2}{|l|}{ Cell constants: } \\
\hline$a$ & 8.5618(10) $\AA$ \\
\hline $\mathrm{b}$ & $8.6657(9) \AA$ \\
\hline c & $22.783(3) \AA$ \\
\hline Volume & $1690.4(3) \AA^{3}$ \\
\hline Z & 4 \\
\hline Density (calculated) & $1.365 \mathrm{Mg} / \mathrm{m}^{3}$ \\
\hline Absorption coefficient & $0.385 \mathrm{~mm}^{-1}$ \\
\hline$F(000)$ & 728 \\
\hline Crystal size & $0.32 \times 0.22 \times 0.12 \mathrm{~mm}^{3}$ \\
\hline Theta range for data collection & 2.51 to $25.39^{\circ}$ \\
\hline Index ranges & $-10 \leq h \leq 10,-10 \leq k \leq 10,-27 \leq \mathrm{I} \leq 27$ \\
\hline Reflections collected & 22569 \\
\hline Independent reflections & $3110[R($ int $)=0.0433]$ \\
\hline Completeness to theta $=25.39^{\circ}$ & $99.8 \%$ \\
\hline Absorption correction & Semi-empirical from equivalents \\
\hline Max. and min. transmission & 0.7452 and 0.4705 \\
\hline Refinement method & Full-matrix least-squares on $\mathrm{F}^{2}$ \\
\hline Data / restraints / parameters & $3110 / 67 / 275$ \\
\hline Goodness-of-fit on $\mathrm{F}^{2}$ & 1.237 \\
\hline Final $R$ indices [l>2sigma(I)] & $\mathrm{R} 1=0.0764, \mathrm{wR} 2=0.1911$ \\
\hline $\mathrm{R}$ indices (all data) & $\mathrm{R} 1=0.0769, \mathrm{wR} 2=0.1913$ \\
\hline $\begin{array}{l}\text { Absolute structure parameter } \\
\text { Largest diff. peak and hole }\end{array}$ & $\begin{array}{l}0.49(19) \\
0.600 \text { and }-0.640 \text { e. } \AA^{-3}\end{array}$ \\
\hline
\end{tabular}


Crystal data and structure refinement for $\mathbf{5 b}$.

\begin{tabular}{|c|c|}
\hline Empirical formula & $\mathrm{C}_{20} \mathrm{H}_{21} \mathrm{~N}_{3}$ \\
\hline Formula weight & 303.40 \\
\hline Temperature & $100(1) \mathrm{K}$ \\
\hline Wavelength & $0.71073 \AA$ \\
\hline Crystal system & monoclinic \\
\hline Space group & $\mathrm{P} 2_{1}$ \\
\hline \multicolumn{2}{|l|}{ Cell constants: } \\
\hline a & $7.1149(3) \AA$ \\
\hline $\mathrm{b}$ & 26.5631(11) $\AA$ \\
\hline C & $8.5150(4) \AA$ \\
\hline$\beta$ & $90.955(3)^{\circ}$ \\
\hline Volume & $1609.06(12) \AA^{3}$ \\
\hline Z & 4 \\
\hline Density (calculated) & $1.252 \mathrm{Mg} / \mathrm{m}^{3}$ \\
\hline Absorption coefficient & $0.075 \mathrm{~mm}^{-1}$ \\
\hline$F(000)$ & 648 \\
\hline Crystal size & $0.12 \times 0.12 \times 0.05 \mathrm{~mm}^{3}$ \\
\hline Theta range for data collection & 1.53 to $25.48^{\circ}$ \\
\hline Index ranges & $-8 \leq \mathrm{h} \leq 8,-31 \leq \mathrm{k} \leq 32,-10 \leq \mathrm{I} \leq 10$ \\
\hline Reflections collected & 29916 \\
\hline Independent reflections & $5858[R$ (int) $=0.0402]$ \\
\hline Completeness to theta $=25.48^{\circ}$ & $99.5 \%$ \\
\hline Absorption correction & Semi-empirical from equivalents \\
\hline Max. and min. transmission & 0.7452 and 0.6245 \\
\hline Refinement method & Full-matrix least-squares on $\mathrm{F}^{2}$ \\
\hline Data / restraints / parameters & $5858 / 1 / 420$ \\
\hline Goodness-of-fit on $F^{2}$ & 1.080 \\
\hline Final $R$ indices [ $\mid>2$ sigma $(I)]$ & $\mathrm{R} 1=0.0632, \mathrm{wR} 2=0.1647$ \\
\hline $\mathrm{R}$ indices (all data) & $\mathrm{R} 1=0.0748, \mathrm{wR} 2=0.1719$ \\
\hline Absolute structure parameter & $2(3)$ \\
\hline Largest diff. peak and hole & 0.485 and -0.238 e. $\AA^{-3}$ \\
\hline
\end{tabular}

